\title{
Overview of the Current State of the Epidemic
}

\author{
Catherine Hankins
}

Published online: 12 April 2013

(C) The Author(s) 2013. This article is published with open access at Springerlink.com

\begin{abstract}
At the end of 2011, about half of the 34.0 million [31.4-35.9 million] people living with HIV infection knew their HIV status. With large regional variations, an estimated $0.8 \%$ of all adults aged 15 to 49 years have HIV infection and HIV subtype diversity is increasing. Although HIV incidence has declined in 39 countries, it is stable or increasing in others. HIV prevalence continues to rise as antiretroviral treatment scale-up results in fewer HIV-related deaths while new infections continue to occur. Increased treatment uptake is likely reducing HIV transmission in countries with large mortality declines. Key populations, including sex workers, men who have sex with men, transgender people, people who inject drugs and young women in high prevalence settings require effective prevention programs urgently. Correcting mismatches in resource allocation and reducing community viral load will accelerate incidence declines and affect future epidemic trends, if concerted action is taken now.
\end{abstract}

Keywords HIV · AIDS · HIV prevalence · HIV incidence · HIV-related mortality · Global epidemic trends · Country responses $\cdot$ Key populations $\cdot$ Community viral load

\section{Introduction}

More than 30 years have passed since the first cases of what would subsequently be known as acquired immunodeficiency syndrome (AIDS) were diagnosed in New York City and

\section{Hankins $(\bowtie)$}

Department of Global Health, Academic Medical Centre,

Amsterdam Institute for Global Health and Development, University of Amsterdam, Trinity Building C, Pietersbergweg 17, PO Box 22700, 1100 DE Amsterdam, Netherlands e-mail: c.hankins@aighd.org

C. Hankins

London School of Hygiene and Tropical Medicine,

London, England
California [1]. On the scientific front, tremendous progress has been made in identifying a retrovirus, the human immunodeficiency virus (HIV), as the cause of AIDS [2••], devising diagnostic tests [3] and developing effective antiretroviral treatment (ART) regimens [4]. On the public health front, HIV prevention approaches based on awareness raising about the need for behavior change, offers of HIV testing and counselling, and promotion of correct and consistent male and female condom use have led to declines in HIV incidence in many countries. New biomedical HIV prevention modalities, such as voluntary medical male circumcision (VMMC) [5], oral pre-exposure prophylaxis (oral PrEP) [6], topical PrEP (microbicides) [7], and early ART for prevention $[8 \cdot \bullet$ purposes are showing promise. At the same time, there is increasing recognition that the structural determinants of HIV risk undermine people's capacity to avoid HIV exposure and acquisition and, if they already have HIV infection, to prevent onward transmission.

On the one hand, there is much to celebrate. The numbers of new cases of HIV infection in both adults and children are falling, fewer people living with HIV are dying from AIDSrelated causes, and enabling policy frameworks have been implemented to structure and speed progress against the HIV epidemic. On the other hand, the size and nature of the challenges before us underscore the fact that, despite persistent and intensifying scientific efforts to find a cure [9•] and to create an efficacious vaccine [10], the HIV epidemic will be with us for decades to come. In summarizing the current state of the HIV epidemic, this article will permit readers to determine for themselves whether the glass is optimistically 'half-full' or soberly 'half-empty'.

\section{Global Figures and Epidemic Trends}

Across the globe at the end of 2011, 34.0 million [range of uncertainty: 31.4-35.9 million] people were living with HIV infection [11], of whom about $50 \%$ know their HIV status 
[12]. Globally, $0.8 \%$ of all adults aged 15 to 49 years have HIV infection. The global figures mask large regional differences, with sub-Saharan Africa (SSA) continuing to shoulder the largest burden, with $69 \%$ of all prevalent HIV infections and close to 1 in 20 adults (4.9\%) living with HIV. One-third of all people with HIV globally reside in 9 countries in southern Africa that account for $2 \%$ of the world's population [13]. In terms of numbers of infections, the next most affected region is South and South-East Asia and, when East Asia is added, the overall Asia region is home to almost 5 million people living with HIV. Three other regions follow, each with 1.4 million people living with HIV: Eastern Europe and Central Asia, North America, and Latin America. The remaining 4 regions are home to 1.49 million people in total, completing the ten-region picture of prevalent HIV infections. The ranges around the UNAIDS estimates (Table 1) define the boundaries within which the actual numbers lie, based on the best available information. They remain relatively wide, reflecting the incomplete picture that current data provide.

Every single one of the 10 regions has experienced an increase in HIV prevalence, comparing 2011 with 2001, with the exception of the Caribbean region that had an apparent decline in its point estimate from 240,000 in 2001 to 230,000 in 2011. For South and South East Asia, Latin America, the Caribbean, and North America the 2011-point estimates lie within the 2001 ranges of uncertainty, suggesting that observed increases might not be significant. However, for the other 6 regions, sub-Saharan Africa, Eastern Europe and Central Asia, Western and Central Europe, East Asia, the Middle East, North Africa, and Oceania, the 2011-point estimate is clearly outside the 2001 range, signalling a likely significant increase in the numbers of people living with HIV.

HIV prevalence can rise if people are living longer with HIV as a result of life-prolonging antiretroviral therapy or if increasing numbers of people are newly acquiring HIV infection. Steadily increasing access to antiretroviral therapy is estimated to have added 14 million life-years in low- and middle-income countries (LMIC) since 1995, with 8 million people on ART at the end of 2011, a 20-fold increase since 2003 [11]. The result has been that from the mid-2000s the number of people dying of AIDS-related causes has fallen steadily. This is reflected in global tuberculosis-related AIDS deaths declining $9 \%$ from 2005 to 2009 and $13 \%$ from 2009 to 2011 [14]. However, age-standardised death rates in the two decades between 1990 and 2010 paint a different picture: the decline of $21.5 \%$ in all cause death rates contrasts starkly to the $258 \%$ increase in the age-standardised death rate for AIDS [15]. Similarly, years lived with disability per 100,000 globally increased only $2.5 \%$ for all causes versus $109.4 \%$ for HIV between 1990 and 2010 [16].

While absolute numbers of deaths due to HIV have been declining, HIV incidence, ie, new HIV infections, has also declined, falling from 3.2 million (2.9-3.4 million) in 2001 to 2.5 million (2.2-2.8 million) in 2011 , despite an expanding world population. Two-thirds of the new HIV infections averted in 2010 and 2011 were those that would have occurred among infants. In fact, new infections in children over these 2 years decreased by $24 \%$ [12]. This is primarily due to increasing program coverage for the prevention of mother-to-child transmission (PMTCT). This decline is set to accelerate now as the Global Plan toward elimination of new infections in children by 2015 gathers speed [17].

The overall incidence decline, which began from a peak in 1997, partially counterbalances increasing HIV prevalence due to ART expansion (Fig. 1). Each person with HIV infection will eventually require ART. An estimated 6.8 million people who are currently eligible for ART do not have access to it [11]. The 2015 goal of 15 million people on ART, known as ' 15 by 15 ', means that these people who are already eligible, as well as others who will become eligible for treatment, need to be reached with treatment services by
Table 1 HIV prevalence by region

\begin{tabular}{llcrr}
\hline Region & $\begin{array}{l}\text { Adults and } \\
\text { children with HIV }\end{array}$ & \multicolumn{2}{l}{ Range } & $\begin{array}{c}\text { Prevalence } \\
\text { age 15-49 }\end{array}$ \\
\hline Sub-Saharan Africa & 23.5 million & $22.1-24.8$ million & 4.9 & $4.6-5.1$ \\
South and South-East Asia & 4.0 million & $3.1-4.6$ million & 0.3 & $0.2-0.3$ \\
East Asia & 830,000 & $590,000-1.2$ million & 0.1 & $<0.1-0.1$ \\
Eastern Europe and Central Asia & 1.4 million & $1.1-1.7$ million & 0.4 & $0.3-0.5$ \\
North America & 1.4 million & $1.1-1.8$ million & 1.0 & $0.6-1.0$ \\
Latin America & 1.4 million & $1.1-2.0$ million & 0.6 & $0.5-1.0$ \\
West and Central Europe & 900,000 & $830,000-1.0$ million & 0.2 & $0.2-0.3$ \\
Middle, East, and North Africa & 300,000 & $250,000-360,000$ & 0.2 & $0.1-0.2$ \\
Caribbean & 230,000 & $200,000-250,000$ & 1.0 & $0.9-1.1$ \\
Oceania & 53,000 & $47,000-60,000$ & 0.3 & $0.2-0.3$ \\
\hline
\end{tabular}


Fig. 1 Global HIV trends, 1990-2011. Global Report [11]
NUMBER OF PEOPLE LIVING WITH HIV, GLOBAL, 1990-2011

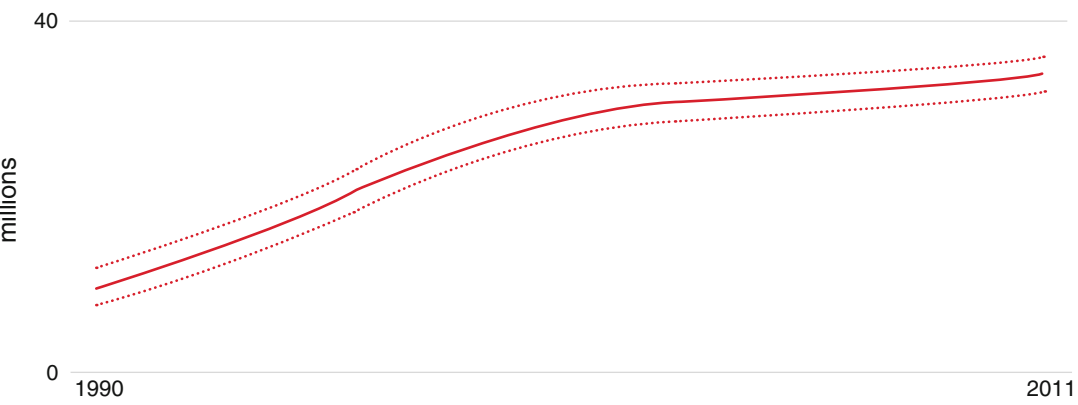

NUMBER OF PEOPLE NEWLY INFECTED WITH HIV, GLOBAL, 1990-2011

5

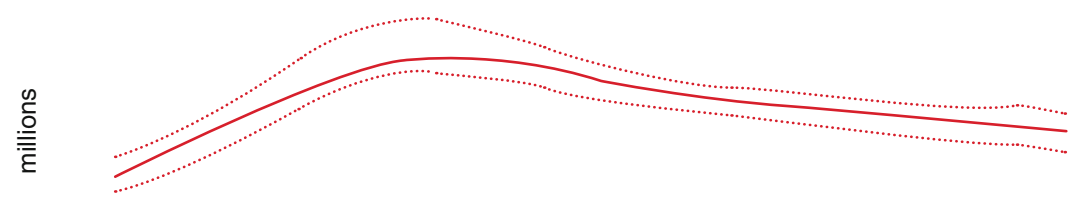

0 1990

2011

3

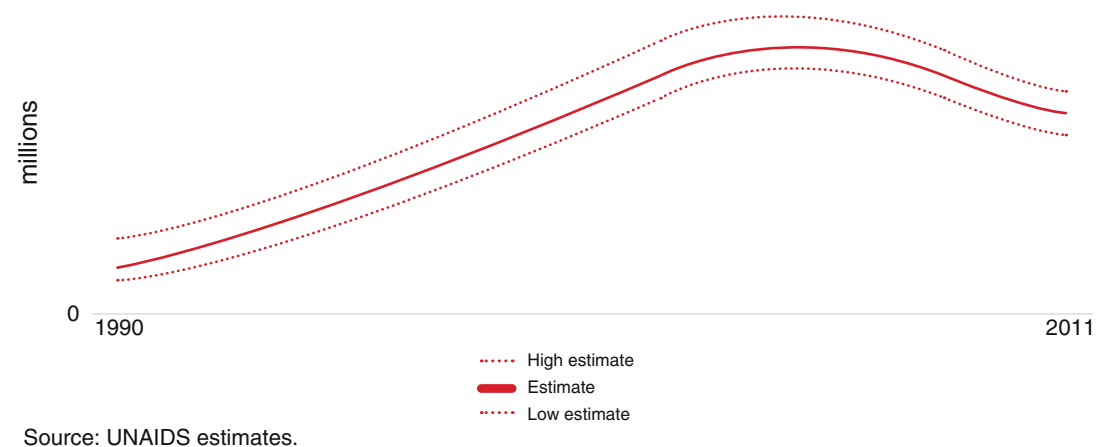

2015. The 2010 World Health Organization ART guidelines recommend treatment initiation when $\mathrm{CD} 4$ cell counts fall to 350 cells/uL [4], however, in high-income countries, increasingly people are starting ART at 500 cells/uL as the benefits of earlier treatment become evident. The definitive answer about individual clinical benefits of early treatment is expected from the START (Strategic Timing of Antiretroviral Therapy) trial underway in 35 countries that will soon complete enrolment of 4000 people with CD4 counts above 500 cells/uL [18]. Participants are being randomized to start treatment immediately or wait until reaching CD4 350 cells, with follow-up planned out to December 2015. Pending the START trial results, there is increasing interest in a 'test and treat' approach [19], in which people, particularly those more likely to be lost to follow-up after an HIV diagnosis, may be offered ART at the time of HIV diagnosis regardless of CD4 count.
Thus, growing numbers of people worldwide will be placed on life-saving ART in the coming years, whether treatment eligibility remains at CD4 350 or it increases to 500, as guidelines and practices change. The result will be increasing longevity for people living with HIV and continued growth in the size of the global epidemic, despite the progress being made to stop the constant incoming flow of new HIV infections.

As the number of people living with HIV continues to expand, HIV subtype diversity will likely increase as HIV continues to evolve through mutation and recombination. Although the global HIV epidemic arose from a handful of HIV group M viruses [20] that jumped species in the Congo River basin likely around 1908, the HIV epidemic today is very diverse $[21 \bullet \bullet]$. Advances in genomic sequencing methods, such as deep DNA sequencing, have greatly improved our understanding and analysis of HIV genetic diversity and the geographical distribution of subtypes. HIV-1 
is now categorized into groups $\mathrm{M}$ (main), $\mathrm{N}$ (non- $\mathrm{M}$, non-O), $\mathrm{O}$ (outlier), and a tentative new group $\mathrm{P}$. Group $\mathrm{M}$ has 9 subtypes or clades (A-D, F-H, J, and K), 51 circulating recombinant forms (CRF), and a large number of unique recombinant forms (URFs) [22]. Recombinant forms are created in the presence of simultaneous or sequential infection with 2 or more different HIV-1 subtypes through strand transfer during reverse transcription [23]. Phylodynamic approaches are increasingly being used to obtain estimates of sequence evolution rates and epidemic network parameters [24], with mathematical modelling demonstrating that inter-subtype recombination has clearly been a substantial force in generating HIV-1 group M diversity [25]. Some regions, such as southern Africa, have low viral diversity, whereas others have several subtypes and circulating recombinants. Subtype $\mathrm{C}$ accounts for $48 \%$ of infections while subtypes A and B account for $12 \%$ and $11 \%$ of global HIV infections respectively [26].

Subtype specificity may be important for vaccine development but does subtype matter for HIV progression and transmission? Certain subtypes are now known to be associated with faster HIV disease progression. Subtype D is associated with higher viral load set points [27] and has a higher frequency of syncytium formation and CXCR4 receptor use associated with more rapid decreases in CD4 cell count. Similar rapid CD4 declines are seen in infection with multiple subtypes compared with infection with a single subtype [28, 29]. This underscores the importance of the positive dignity, health, and prevention strategy in reducing the risk of superinfection [30]. Subtype C strains use CCR5 receptors and rarely switch to using CXCR4 or both, a switch that is normally associated with more rapid disease progression. This may explain the slower progression seen in people with subtype C compared with subtype D or A [31]. As for whether certain subtypes are more easily transmitted, a study in Uganda found that subtype A was more readily transmitted heterosexually than subtype D [32]. Individuals who have high viral set points and those who maintain high viral loads in the absence of ART are more likely to transmit HIV infection [33], suggesting that they would be priority candidates for early ART. Given the increasing recognition of the powerful prevention benefits of ART through substantially reduced transmission when viral load is suppressed [8••], ART scaleup will have important effects in decreasing HIV incidence globally at the same time that it will increase HIV prevalence.

\section{National Responses and Trends}

Some countries have made striking progress in preventing new HIV infections while others lag behind and a few even have increasing HIV incidence. For example, among 18 subSaharan African countries with an HIV prevalence of $3 \%$ or more in 2011, Swaziland, South Africa, and Mozambique had increasing HIV prevalence over the previous decade but significantly declining HIV incidence (Table 2) while Uganda experienced an increase in HIV prevalence along with a $22 \%$ increase in HIV incidence (Table 3 ).

In 2012, 186 countries, representing $96 \%$ of United Nations member states, submitted comprehensive reports on their national AIDS responses to UNAIDS. These reports highlight how well a country is performing in meeting the 2015 targets that all countries agreed to when they signed on to the 2011 United Nations Political Declaration on HIV and AIDS: Intensifying our efforts to eliminate HIV and AIDS [34] The combination of these national AIDS response reports, which include ART and prevention program coverage, with countryspecific estimates for HIV prevalence, AIDS-related mortality, and HIV incidence, help paint a picture of what responses in which countries are the most effective in addressing HIV. Recent epidemic trends are analyzed by UNAIDS using published peer-reviewed articles or through the use of recommended modelling tools for national HIV estimations [35].

HIV incidence in adults 15-49 years old fell by more than $50 \%$ in the decade from 2001 to 2011 in 25 countries, 12 of which are in sub-Saharan Africa, 6 in the Caribbean, 6 in Asia, and 1 in the Middle East. The sharpest regional declines were in the Caribbean (42\%) and sub-Saharan Africa (25\%) [11]. Over the same period, adult HIV incidence increased by more than $25 \%$ in 9 countries, 4 of which are in Eastern Europe and Central Asia (Georgia, Kazakhstan, Kyrgyzstan, and the Republic of Moldova), 4 are in Asia (Bangladesh, Indonesia, Philippines, and Sri Lanka), and only 1 is in Africa (Guinea Bissau). Of note, the numbers of new HIV infections had been relatively stable in Eastern Europe and Central Asia until the late 2000s when the increase began.

Is ART scale-up playing a role in country HIV incidence declines? A clinical trial among discordant couples in 9 countries found a $96 \%$ reduction in the risk of genetically-linked HIV transmission when early ART at CD4 counts above 350 supressed viral load in the HIV-infected partner [8••]. In the absence of treatment, infectivity is estimated to be 9 times higher in early HIV infection and 7 times higher in late HIV infection [36]. Further, the utility of mathematical modelling to examine the potential impact of ART on HIV incidence has been explored, with a study of 12 models [37] finding broad agreement regarding the short-term epidemiologic impact of ambitious treatment scale-up, but more variation in longer term projections and in the efficiency with which treatment can reduce new infections [38].

An examination of trends in mortality could allow an assessment of the possible role of ART scale-up in contributing to declining HIV incidence. In fact, of the 14 countries that have experienced a $50 \%$ decline in mortality between 2005 and 2011, 7 of them had achieved $80 \%$ or more coverage of ART for eligible people and 3 had achieved $60 \%-79 \%$ coverage. Nine of the 14 countries with these large mortality 
Table 2 African countries with HIV prevalence greater than $10 \%$ in 2011

\begin{tabular}{|c|c|c|c|c|c|}
\hline Countries & 2001 & & 2011 & & 2001-2011 \\
\hline & Prevalence & Incidence & Prevalence & Incidence & $\begin{array}{l}\% \text { Change in } \\
\text { Incidence }\end{array}$ \\
\hline Swaziland & 22.2 & 4.11 & 26.0 & 2.60 & $-37 \%$ \\
\hline Botswana & 27.0 & 3.48 & 23.4 & 1.00 & $-71 \%$ \\
\hline Lesotho & 23.4 & 2.67 & 23.3 & 2.47 & $-7 \%$ \\
\hline South Africa & 15.9 & 2.42 & 17.3 & 1.43 & $-41 \%$ \\
\hline Zimbabwe & 25.0 & 2.11 & 14.9 & 1.05 & $-50 \%$ \\
\hline Zambia & 14.4 & 1.89 & 12.5 & 0.80 & $-58 \%$ \\
\hline Namibia & 15.5 & 2.39 & 13.4 & 0.77 & $-68 \%$ \\
\hline Mozambique & 9.7 & 1.63 & 11.3 & 1.13 & $-31 \%$ \\
\hline Malawi & 13.8 & 1.74 & 10.0 & 0.49 & $-72 \%$ \\
\hline
\end{tabular}

Source: UNAIDS Report on the Global AIDS Epidemic - 2012. Accessible at: http://www.unaids.org/en/media/unaids/contentassets/documents/ epidemiology/2012/gr2012/JC2417_GR\%202012_Annexes_en.pdf and http://www.unaids.org/en/dataanalysis/knowyourepidemic/ epidemiologicalfactsheets/

Note: Green shading indicates significant decrease in incidence or prevalence; yellow shading indicates moderate decrease in incidence or prevalence; red shading indicates increase in incidence or prevalence

declines had a greater than $50 \%$ decline in incidence from 2001-2011 [11]. This suggests that ART scale-up is likely influencing HIV transmission; however the extent remains to be determined.
What about the contribution of HIV prevention programming to declining HIV incidence? UN member states have pledged to meet Universal Access Targets [39] and Millennium Development Goals [40] and have committed,

Table 3 African countries with HIV prevalence between $3 \%$ and $10 \%$ in 2011

\begin{tabular}{|l|l|l|l|l|l|}
\hline & Countries & 2001 & \multicolumn{5}{c}{2011} & 2001-2011 \\
& Prevalence & Incidence & Prevalence & Incidence & $\begin{array}{l}\% \text { Change in } \\
\text { Incidence }\end{array}$ \\
\hline Cote d'Ivoire & 6.2 & 0.39 & 3.0 & $0.15^{\mathrm{a}}$ & $-54 \%$ \\
\hline Uganda & 6.9 & 0.69 & 7.2 & 0.84 & $+22 \%$ \\
\hline Tanzania & 7.2 & 0.62 & 5.8 & 0.59 & $-5 \%$ \\
\hline Kenya & 8.5 & 0.66 & 6.2 & 0.45 & $-\mathbf{3 2} \%$ \\
\hline CAR & 8.1 & 0.67 & 4.6 & 0.29 & $-\mathbf{5 7 \%}$ \\
\hline Cameroon & 5.1 & 0.63 & 4.6 & 0.36 & $-\mathbf{4 3} \%$ \\
\hline Chad & 3.7 & $\mathrm{nd}$ & 3.1 & 0.28 & $\mathrm{nd}$ \\
\hline Congo & 3.8 & 0.35 & 3.3 & 0.31 & $-\mathbf{1 1} \%$ \\
\hline Nigeria & 3.7 & 0.42 & 3.7 & 0.36 & $-\mathbf{1 4} \%$ \\
\hline
\end{tabular}

Source: UNAIDS Report on the Global AIDS Epidemic - 2012. Accessible at: http://www.unaids.org/en/media/unaids/contentassets/documents/ epidemiology/2012/gr2012/JC2417_GR\%202012_Annexes_en.pdf and http://www.unaids.org/en/dataanalysis/knowyourepidemic/ epidemiologicalfactsheets/

Note: Green shading indicates significant decrease in incidence or prevalence; yellow shading indicates moderate decrease in incidence or prevalence; red shading indicates increase in incidence or prevalence

a 2009 data 
for example, to $50 \%$ reductions in sexual transmission and $50 \%$ reductions in injecting drug use-related transmission by 2015 . To accomplish this, and other prevention goals such as the elimination of new HIV infections in children, countries are strengthening their combination prevention programs. Combination prevention combines behavioral, biomedical, and structural interventions to address both the immediate risks and underlying causes of vulnerability to HIV infection, as well as the pathways that link them [41]. It is evidence-informed, human-rights based, and contextspecific. In order to be effective, prevention programs must be tailored to local epidemics, with relevant components delivered at an intensity, quality, and scale necessary to achieve intended effects. Some countries have used the 'Know Your Epidemic, Know Your Response' process to discover the extent of disconnects between the dynamics of their epidemic and the resources they have committed to addressing it [42]. Although this process can lead to realignment of resources for improved cost-effectiveness, a recent analysis of HIV prevention spending in 69 low- and middle-income countries with a variety of epidemic types revealed that spending patterns did not consistently reflect either current evidence or the HIV-specific context of each country [43•]. Recognition of the culture-specific aspects of microepidemics in a country is an important first step toward development of community-based organizations that can foster locally effective HIV responses [44]. In fact, bold and collaborative leadership in local scale-up of HIV prevention and treatment has been shown to underpin success in countries as varied as Brazil, Botswana, Nigeria, and India [45].

With respect to sexual transmission of HIV, effective HIV prevention programs can contribute to declining incidence trends when they foster changes in sexual behavior toward healthier patterns. Such prevention programming focuses on increasing knowledge, raising awareness, building skills, and creating safer sexual social norms. The agreed indicators being tracked are sex before age 15 years, as reported by young people age 15 to 24 years, and multiple partners in the previous 12 months and condom use at last high-risk sex, as reported by those aged 15-49 years. In 11 countries with adult HIV prevalence greater than $1 \%, 5$ of which experienced a greater than $50 \%$ decline in HIV incidence, significantly fewer young women are reporting sex before age 15 years [11], suggesting that delayed sexual debut may be contributing to reduced HIV incidence. Changes in the indicators for adult sexual behavior are most striking in 3 countries with $50 \%$ declines (Zambia, Malawi, and Namibia), 2 countries with $26 \%-49 \%$ decreases (Kenya and Mozambique), and 1 country with stable incidence but a very large population (Nigeria). However, risky sex is on the increase in some countries (Cote d'Ivoire, Guyana, and Rwanda) and comprehensive and correct knowledge about HIV and its transmission is suboptimal in many countries that have an adult HIV prevalence over $1 \%$. For example, less than $50 \%$ of young women in 26 of 31 countries and less than $50 \%$ of young men in 21 of 25 countries conducting surveys had adequate HIV-related knowledge [11].

Progress on increasing access to voluntary medical male circumcision (VMMC) has been slow but steady since WHO/UNAIDS recommended the procedure to reduce the risk of sexual HIV acquisition in young men living in countries with higher HIV prevalence [5]. The potential impact is impressive, with mathematical modelling estimating 16.5 billion USD in cost savings by 2025 in averted HIV infections for a 1.5 billion USD investment to reach $80 \%$ circumcision prevalence by 2015 in the countries with the heaviest HIV burdens [46]. Kenya, Ethiopia, and Swaziland have made the most progress, attaining $20 \%$ of their national targets. In Ethiopia and Swaziland infant male circumcision is now offered to parents routinely. But the promise of male circumcision will not be realized without task shifting and the use of timesaving devices that are currently under evaluation for safety and acceptability [47-49].

\section{Key Populations}

Key populations are defined as those that are key to the dynamics of an epidemic and key to the response to it. Without the explicit and active engagement of a key population in the design, implementation, and evaluation of an HIV prevention program addressing it, the program is likely to fail. Which populations are key will be context-specific but vulnerability, marginalization, and inability to influence the environment within which risk is experienced are hallmarks. Legal and policy barriers in many countries impede HIV prevention programming for sex workers, men who have sex with men, transgendered people, and people who inject drugs. Cultural and economic impediments to education, self-actualization, and financial independence combined with sexual violence heighten HIV risk for young women in southern Africa [50].

Female sex workers were estimated in a systematic review of studies representing almost 100,000 sex workers in 50 countries to have an overall prevalence of $11.8 \%$ and a pooled odds ratio of 13.5 for HIV infection. In 26 countries with medium- and high-background HIV prevalence, HIV prevalence among sex workers rose to $30.7 \%$ with an odds ratio of 11.6 [51•]. Almost $75 \%$ of the 59 countries reporting to UNAIDS about sex work indicated that they had implemented comprehensive prevention programs for sex workers, however, most of these appear to be in urban settings and only 11 countries are reaching at least $80 \%$ of sex workers in cities [11]. Where services are provided, 85 countries report that nearly 9 in 10 sex workers used a condom the last time they had sex [12]. Given the disproportionate HIV burden borne by sex workers and the likelihood of onward HIV transmission, 
this population should be prioritized for increased access to ART and to antiretroviral-based PrEP. However, this has to go hand in hand with anti-stigma, anti-discrimination, and antiviolence programs, as well as legal and policy changes and engagement/empowerment strategies to change the risk environment in which sex work is occurring [52].

Men who have sex with men (MSM) have a disproportionately high HIV burden, as a result of the high per-act and per-partner transmission probabilities during anal sex, and have higher rates of dual-variant and multiple-variant HIV infection than heterosexual people in the same settings [53]. The global prevalence of HIV among MSM appears to have increased from 2010 to 2012, although data are limited and not readily comparable [11]. Although 146 countries now include MSM in their national strategies, only 104 reported HIV prevalence data in 2012, 62 reported prevention program coverage among MSM, 100 reported HIV testing coverage, and 96 reported on condom use. Median prevention coverage in capital cities was $55 \%$, a median of $38 \%$ of MSM received an HIV test in the previous 12 months, and $75 \%$ of MSM in only 13 countries reported condom use at last sex [11]. Although funding for HIV prevention among MSM increased between 2006 and 2011, $92 \%$ of all spending on HIV programs for MSM came from international sources [11]. With a high force of infection and clustering of HIV in MSM networks, antiretroviral-based prevention strategies, whether PrEP for HIV-negative men or ART for HIV-positive men, would help control epidemic expansion but would require culturally competent care accompanied by decriminalization and reduction of stigma and discrimination [54••].

Transgender women, estimated at 15 million globally, are at extremely high risk of HIV acquisition compared with other adults, with HIV prevalence as high as $68 \%$ [55] and an odds ratio of being infected of 48.8 ( $95 \%$ confidence interval 12.2 76.3) without significant differences between high-income and low- and middle-income settings in a recent systematic review and meta-analysis [56•]. Transgender women have a female gender identity but a birth-assigned male sex. Lacking access to information, services, and economic opportunities, up to $44 \%$ of transgender women in high-income countries rely on sex work as their only source of income [57]. A systematic review of studies in 14 countries on 5 continents found that transgender women engaged in sex work are more than 4 times as likely as other female sex workers to be living with HIV [58]. This marginalized highly vulnerable population is below the radar of the majority of national HIV prevention programs, with the result that data on HIV prevalence and program coverage are scarce. Only $43 \%$ of countries report that their national strategies address transgender people and $40 \%$ indicate that government service provision accounts for less than $25 \%$ of the programs and services that are provided [11]. Engaging and empowering transgender women to have a stronger voice is the only pathway to better surveillance data, representation in HIV prevention research in adequate numbers for analysis, effective prevention programs, and promotion and protection of the rights of this neglected key population.

A striking HIV prevalence, 22 times higher than that of the general population, is found in 49 countries among people who inject drugs (PWID), with 11 countries having 50 -fold or more differences [11]. A recent systematic review of studies from 14 countries found a significantly higher HIV prevalence among female compared with male injectors [59], reflecting the increased risks faced by women who inject and who are not reached with HIV prevention services [60]. Although contaminated injecting equipment is the immediate source, augmented by unprotected sexual intercourse, punitive approaches rooted in perceptions of drug injecting as illegal behavior are fuelling expanding epidemics, particularly in Eastern Europe and Central Asia. Globally few countries remain untouched. A systematic review conducted in 2007 found documented injecting drug use in 148 countries, HIV infection associated with injecting in 120 of those countries, and an estimated total of 15.9 million [11.0-21.2 million] PWID, with the largest numbers being in China, the USA, and Russia [61]. Worldwide 3 million (0.8-6 million) PWID may be living with HIV. The HIV prevention evidence base for injecting-related HIV is strong but many countries are neither tracking HIV incidence nor implementing proven effective prevention such as needle-syringe programs (NSP) or opioid substitution treatment (OST). Those that report that they are providing injecting equipment are doing so at a distribution rate of 2 needle-syringes per month, well below the annual minimum threshold of 100 that demarcates low coverage from medium coverage [11]. Among 57 reporting countries, only $39 \%$ of PWID have had an HIV test in the previous 12 months and among 56 reporting countries, only 3 countries reported condom use above $75 \%$ [11]. A global call to action [62] and the 2010 Vienna Declaration [63] emphasize the critical importance of science rather than ideology informing HIV prevention. For example, reducing unmet need among PWID by $60 \%$ for NSP, OST, and ART from 2010 to 2015 , would reduce HIV prevalence by $41 \%, 43 \%$, and $30 \%$ in the cities of Odessa, Karachi, and Nairobi, respectively [64•]. With $30 \%$ of new HIV infections outside sub-Saharan Africa attributed to injecting, pragmatic harm reduction approaches, including experimentation with decriminalization of personal drug use, as Portugal has done [65], are needed to slow this expanding epidemic.

Young women constitute a key population in sub-Saharan Africa, with those aged 15-24 years as much as 8 times more likely than young men to be HIV-positive [66]. Although HIV prevalence in young people aged 15 to 24 years fell more than $35 \%$ between 2001 and 2011 [12], young women, particularly in southern Africa, are still experiencing exceptionally high 
levels of HIV infection. To achieve greater impact on preventing HIV transmission, an aggressive movement for social transformation is required to address both the immediate practices that lead to HIV acquisition as well as the human rights violations, harmful social norms, weak community and leadership capacities, and disparities that underpin HIV risk for women and for men in southern Africa [67]. The first step is mobilization of communities for HIV prevention, with strong male involvement, to design relevant strategies and messages about the causes, consequences of, and solutions to young women and girls' vulnerability, including 'zero tolerance' for gender-based violence and exploitation.

\section{Conclusions}

As global HIV prevalence stabilizes with increasing ART scale-up and declining HIV incidence in many countries, there is increasing interest in determining the mix of programs and strategies that will be most cost-effective in reducing HIV incidence most quickly in given epidemic settings. In addition to correcting mismatches in resource allocation for HIV prevention, the concept of tracking community viral load (CVL) as a population-level biomarker for HIV burden and potential transmission is compelling [68]. CVL is defined as the mean of the most recent viral load test of all people living with HIV within a specified geographic area over a specified period. Ecological studies have demonstrated correlations between decreases in CVL and reductions in HIV incidence. For example, viral load reductions among PWID in Vancouver were associated with decreased incidence in an HIV-negative PWID cohort [69]. Increased uptake of more effective, potent, and tolerable ART regimens in San Francisco between 2005 and 2008, concomitant with legal changes to facilitate HIV testing, policy initiatives to promote expanded HIV testing, increased acute HIV detection, and partner services, coincided with a significant increase in the population rate of virologic suppression from $46.8 \%$ in 2005 to $78.1 \%$ in 2008 . Estimated HIV incidence declined by over one-third between 2006 and 2008 [70••]. New empirical evidence from rural KwaZuluNatal, South Africa has resoundingly shown that individual HIV acquisition risk significantly declines with increasing community ART coverage $[71 \bullet \bullet]$. Finally, CVL could be used to predict the efficacy of early ART for prevention programs [72].

Future trends in the global HIV epidemic will be determined by the actions of individuals, couples, and communities but, ultimately, it will be policy makers, implementers, civil society, and funders that will be held accountable for choosing, implementing, and evaluating tailored prevention packages judged to be optimal in specific circumstances [73], at the same time that they scale up ART with its proven prevention benefits and tangible impact on life expectancy [74]. As the population of people living with HIV continues to age, increasingly attention will need to turn to the challenges of HIV and aging [75]. The potential for accelerated declines in HIV incidence before the advent of an efficacious HIV vaccine is real. The glass is half full and the time to act is now.

Acknowledgments The author thanks Deborah Birx of the Division of Global HIV/AIDS, Center for Global Health, US CDC for data compilation for Tables 2 and 3, and Gabriela Gomez, Marja Nieuwpoort, and Linde Nieuwenhuys of the Amsterdam Institute for Global Health and Development for their assistance with article retrieval and references.

Conflict of Interest Catherine Hankins receives consulting fees from Amsterdam Institute for Global Health and Development.

Open Access This article is distributed under the terms of the Creative Commons Attribution License which permits any use, distribution, and reproduction in any medium, provided the original author(s) and the source are credited.

\section{References}

Papers of particular interest, published recently, have been highlighted as:

- Of importance

-. Of major importance

1. Kaposi's sarcoma and Pneumocystis pneumonia among homosexual men-New York City and California. Morb Mortal Wkly Rep 1981;30:305-8.

2. • Barré-Sinoussi F. HIV: a discovery opening the road to novel scientific knowledge and global health improvement. Virology. 2010;397:255-9. This Nobel Lecture presented by the author in Stockholm in 2008 describes the history of the discovery of HIV, current knowledge on HIV pathogenesis, and lessons from HIV for improving global health.

3. Alvarez M, Chueca N, Guillot V, Bernal MDC, García F. Improving clinical laboratory efficiency: introduction of systems for the diagnosis and monitoring of HIV infection. Open Virol J. 2012;6:135-43.

4. World Health Organization. Antiretroviral therapy for HIV infection in adults and adolescents: recommendations for a public health approach. Geneva: World Health Organization; 2010.

5. WHO, UNAIDS. WHO/UNAIDS technical consultation male circumcision and HIV prevention: research implications for policy and programming Montreux, 6- 8 March 2007: conclusions and recommendations [Internet]. Available at: http://data.unaids.org/ pub/Report $/ 2007 / \mathrm{mc}$ recommendations_en.pdf.

6. Hankins CA, Dybul MR. The promise of pre-exposure prophylaxis with antiretroviral drugs to prevent HIV transmission: a review. Curr Opin HIV AIDS. 2013;8:50-8.

7. Abdool Karim Q, Abdool Karim SS, Frohlich JA, Grobler AC, Baxter C, Mansoor LE, et al. Effectiveness and safety of tenofovir gel, an antiretroviral microbicide, for the prevention of HIV infection in women. Science. 2010;329:1168-74.

8. •• Cohen MS, Chen YQ, McCauley M, Gamble T, Hosseinipour MC, Kumarasamy N, et al. Prevention of HIV-1 infection with early antiretroviral therapy. N Engl J Med. 2011;365:493-505. This 9-country trial (HPTN 052) enrolled 1763 serodiscordant couples randomized to have the HIV-positive partner receive early 
antiretroviral therapy at CD4 cell counts between 350 and 550 cells $/ \mathrm{ml}$. It demonstrated a $96 \%$ reduction in the risk of genotypically-linked HIV transmission to the HIV-negative partner, interpreted widely as 'treatment for prevention'.

9. - Deeks SG, Autran B, Berkhout B, Benkirane M, Cairns S, Chomont N, et al. Toward an HIV cure: a global scientific strategy. Nat Rev Immunol. 2012;12:607-14. This article lays out a strategic framework to guide research into a cure for HIV that would both stop HIV transmission to those who are uninfected and restore immunological competence and normal health to those who are infected. It describes mechanisms of HIV persistence during antiretroviral therapy, presents information on the 'Berlin patient', and lists 7 key scientific priorities for HIV cure research.

10. Kim JH, Rerks-Ngarm S, Excler J-L, Michael NL. HIV vaccines: lessons learned and the way forward. Curr Opin HIV AIDS. 2010;5:428-34.

11. UNAIDS. Global Report 2012 UNAIDS Report on the Global AIDS Epidemic. United Nations Publications; 2012.

12. UNAIDS. UNAIDS World AIDS Day Report. United Nations Publications. 2012.

13. De Cock KM, Jaffe HW, Curran JW. The evolving epidemiology of HIV/AIDS. AIDS. 2012;26:1205-13.

14. World Health Organization. Global tuberculosis report 2012 [Internet]. 2012. Available at: http://www.who.int/iris/bitstream/ 10665/75938/1/9789241564502_eng.pdf. Accessed Jan 11, 2013.

15. Lozano R, Naghavi M, Foreman K, Lim S, Shibuya K, Aboyans V, et al. Global and regional mortality from 235 causes of death for 20 age groups in 1990 and 2010: a systematic analysis for the Global Burden of Disease Study 2010. Lancet. 2012 Dec 15;380(9859):2095-128. doi:10.1016/S0140-6736(12)61728-0.

16. Vos T, Flaxman AD, Naghavi M, Lozano R, Michaud C, Ezzati M, et al. Years lived with disability (YLDs) for 1160 sequelae of 289 diseases and injuries 1990-2010: a systematic analysis for the Global Burden of Disease Study 2010. Lancet. 2012 Dec 15;380(9859):2163-96. doi:10.1016/S0140-6736(12)61729-2.

17. Countdown to zero global plan towards the elimination of new HIV infections among children by 2015 and keeping their mothers alive, 2011-2015. World Health Organization; 2012.

18. The Start Study [Internet]. Available at: http://thestartstudy.org/ learnmore.html. Accessed Dec 30, 2012.

19. Gardner EM, McLees MP, Steiner JF, Del Rio C, Burman WJ. The spectrum of engagement in HIV care and its relevance to test-andtreat strategies for prevention of HIV infection. Clin Infect Dis. 2011;52:793-800.

20. Worobey M, Gemmel M, Teuwen DE, Haselkorn T, Kunstman K, Bunce M, et al. Direct evidence of extensive diversity of HIV-1 in Kinshasa by 1960 . Nature. 2008;455:661-4.

21. - Hemelaar J. The origin and diversity of the HIV-1 pandemic. Trends Mol Med. 2012;18:182-92. This review summarizes current understanding of the origin of HIV, HIV genetic variability resulting from high mutation and recombination rates, and the impact of global HIV diversity on the HIV pandemic.

22. Kiwelu IE, Novitsky V, Margolin L, Baca J, Manongi R, Sam N, et al. HIV-1 subtypes and recombinants in Northern Tanzania: distribution of viral quasispecies. PLoS One. 2012;7:e47605.

23. Shao Y, Williamson C. The HIV-1 epidemic: low- to middle-income countries. Cold Spring Harb Perspect Med. 2012;2:a007187.

24. Vermund SH, Leigh-Brown AJ. The HIV epidemic: high-income countries. Cold Spring Harb Perspect Med. 2012;2:a007195.

25. Ward MJ, Lycett SJ, Kalish ML, Rambaut A, Leigh Brown AJ. Estimating the rate of inter-subtype recombination in early HIV-1 group M strains. J Virol. 2013;87(4):1967-73. doi:10.1128/ JVI.02478-12.

26. Hemelaar J, Gouws E, Ghys PD, Osmanov S. Global trends in molecular epidemiology of HIV-1 during 2000-2007. AIDS. 2011;25:679-89.
27. Morrison CS, Demers K, Kwok C, Bulime S, Rinaldi A, Munjoma $\mathrm{M}$, et al. Plasma and cervical viral loads among Ugandan and Zimbabwean women during acute and early HIV-1 infection. AIDS. 2010;24:573-82.

28. Kiwanuka N, Laeyendecker O, Robb M, Kigozi G, Arroyo M, McCutchan F, et al. Effect of human immunodeficiency virus Type 1 (HIV-1) subtype on disease progression in persons from Rakai, Uganda, with incident HIV-1 infection. J Infect Dis. 2008;197:707-13.

29. Sagar M, Lavreys L, Baeten JM, Richardson BA, Mandaliya K, Chohan $\mathrm{BH}$, et al. Infection with multiple human immunodeficiency virus type 1 variants is associated with faster disease progression. $\mathrm{J}$ Virol. 2003;77:12921-6.

30. The Global Network of People Living with HIV, UNAIDS. Positive health, dignity and prevention: a policy framework [Internet]. 2011. Available at: http://www.unaids.org/en/media/ unaids/contentassets/documents/unaidspublication/2011/ 20110701 phdp.pdf. Accessed Jan 7, 2013.

31. Tebit DM, Arts EJ. Tracking a century of global expansion and evolution of HIV to drive understanding and to combat disease. Lancet Infect Dis. 2011;11:45-56.

32. Kiwanuka N, Laeyendecker O, Quinn TC, Wawer MJ, Shepherd J, Robb M, et al. HIV-1 subtypes and differences in heterosexual HIV transmission among HIV-discordant couples in Rakai, Uganda. AIDS. 2009;23:2479-84.

33. Novitsky V, Wang R, Bussmann H, Lockman S, Baum M, Shapiro $\mathrm{R}$, et al. HIV-1 subtype $\mathrm{C}$-infected individuals maintaining high viral load as potential targets for the "test-and-treat" approach to reduce HIV transmission. PLoS One. 2010;5:e10148.

34. Political declaration on HIV and AIDS: intensifying our efforts to eliminate HIV and AIDS [Internet]. Available at: http:// www.unaids.org/en/media/unaids/contentassets/documents/document/2011/06/20110610_un_a-res-65-277_en.pdf. Accessed Jan 11,2013

35. Stover J, Brown T, Marston M. Updates to the spectrum/estimation and projection package (EPP) model to estimate HIV trends for adults and children. Sex Transm Infect. 2012;88 Suppl 2:111-6.

36. Boily M-C, Baggaley RF, Wang L, Masse B, White RG, Hayes RJ, et al. Heterosexual risk of HIV-1 infection per sexual act: systematic review and meta-analysis of observational studies. Lancet Infect Dis. 2009;9:118-29.

37. Eaton JW, Johnson LF, Salomon JA, Bärnighausen T, Bendavid E, Bershteyn A, et al. HIV treatment as prevention: systematic comparison of mathematical models of the potential impact of antiretroviral therapy on HIV incidence in South Africa. PLoS Med. 2012;9:e1001245.

38. The HIV. Modelling Consortium Treatment as Prevention Editorial Writing Group. HIV treatment as prevention: models, data, and questions - towards evidence-based decision-making. PLoS Med. 2012;9:e1001259.

39. World Health Organization, UNAIDS, Unicef. Global HIV/AIDS response: epidemic update and health sector progress towards universal access: progress report 2011. Geneva: World Health Organization; 2011.

40. UN. Millennium Development Goials [Internet]. Available at: http://www.un.org/millenniumgoals/. Accessed Jan 11, 2013.

41. Hankins CA, De Zalduondo BO. Combination prevention: a deeper understanding of effective HIV prevention. AIDS. 2010;24 Suppl 4:S70-80.

42. Gouws E, White PJ, Stover J, Brown T. Short term estimates of adult HIV incidence by mode of transmission: Kenya and Thailand as examples. Sex Transm Infect. 2006;82 Suppl 3:iii51-5.

43. - Amico P, Gobet B, Avila-Figueroa C, Aran C, De Lay P. Pattern and levels of spending allocated to HIV prevention programs in low- and middle-income countries. BMC Publ Health. 2012;12:221. This analysis of country HIV prevention spending data used National AIDS Spending Assessment (NASA) methods 
and classifications. HIV prevention received 21\% of AIDS funding and relied heavily on international donors. Only 7\% of funding was spent on key populations.

44. Mayer KH, Pape JW, Wilson P, Diallo DD, Saavedra J, Mimiaga MJ, et al. Multiple determinants, common vulnerabilities, and creative responses: addressing the AIDS pandemic in diverse populations globally. J Acquir Immune Defic Syndr. 2012;60 Suppl 2:S31-4.

45. Kanki P, Kakkattil P, Simao M. Scaling up HIV treatment and prevention through national responses and innovative leadership. J Acquir Immune Defic Syndr. 2012;60 Suppl 2:S27-30.

46. Hankins C, Forsythe S, Njeuhmeli E. Voluntary medical male circumcision: an introduction to the cost, impact, and challenges of accelerated scaling up. PLoS Med. 2011;8:e1001127.

47. Barone MA, Ndede F, Li PS, Masson P, Awori Q, Okech J, et al. The Shang Ring device for adult male circumcision: a proof of concept study in Kenya. J Acquir Immune Defic Syndr. 2011;57:e7-e12.

48. Bitega JP, Ngeruka ML, Hategekimana T, Asiimwe A, Binagwaho A. Safety and efficacy of the PrePex device for rapid scale-up of male circumcision for HIV prevention in resource-limited settings. J Acquir Immune Defic Syndr. 2011;58:e127-34.

49. Musau P, Demirelli M, Muraguri N, Ndwiga F, Wainaina D, Ali NA. The safety profile and acceptability of a disposable male circumcision device in Kenyan men undergoing voluntary medical male circumcision. J Urol. 2011;186:1923-7.

50. Shannon K, Leiter K, Phaladze N, Hlanze Z, Tsai AC, Heisler M, et al. Gender inequity norms are associated with increased maleperpetrated rape and sexual risks for HIV infection in Botswana and Swaziland. PLoS One. 2012;7:e28739.

51. Baral S, Beyrer C, Muessig K, Poteat T, Wirtz AL, Decker MR, et al. Burden of HIV among female sex workers in low-income and middleincome countries: a systematic review and meta-analysis. Lancet Infect Dis. 2012 Jul;12(7):538-49. doi:10.1016/S1473-3099(12)70066-X.

52. Joint United Nations Program on HIV/AIDS. UNAIDS guidance note on HIV and sex work. [Geneva]: UNAIDS; 2009.

53. Beyrer C, Baral SD, Van Griensven F, Goodreau SM, Chariyalertsak $\mathrm{S}$, Wirtz AL, et al. Global epidemiology of HIV infection in men who have sex with men. Lancet. 2012;380:367-77.

54. • Beyrer C, Sullivan PS, Sanchez J, Dowdy D, Altman D, Trapence G, et al. A call to action for comprehensive HIV services for men who have sex with men. Lancet. 2012;380:424-38. This call to action summarizes the evidence base for comprehensive HIV prevention, treatment, and care for men who have sex with men (MSM) and presents a research agenda before laying out concrete actions to be taken by governments, Ministries of Health, donors, researchers, and community members. It presents the human rights arguments, justifies the repeal of punitive laws for public health impact, describes an accountability method for assessing the HIV response among gay men and other MSM, and defines an action timeline for a strategy on HIV in MSM.

55. World Health Organization. Prevention and treatment of HIV and other sexually transmitted infections among men who have sex with men and transgender people: recommendations for a public health approach, 2011. [Internet]. Geneva, Switzerland: World Health Organization; 2011. Available at: http://whqlibdoc.who.int/ publications/2011/9789241501750 eng.pdf. Accessed Jan 11, 2013.

56. • Baral SD, Poteat T, Strömdahl S, Wirtz AL, Guadamuz TE, Beyrer C. Worldwide burden of HIV in transgender women: a systematic review and meta-analysis. Lancet Infect Dis. 2013;13(3):214-22. doi: 10.1016/S1473-3099(12)70315-8. This systematic review and metaanalysis of HIV in transgender women found data only from countries with male-predominant HIV epidemics. Consistently across countries, this population bears a very high HIV burden and urgently needs HIV prevention, treatment, and care services.

57. Schulden JD, Song B, Barros A, Mares-DelGrasso A, Martin CW, Ramirez R, et al. Rapid HIV testing in transgender communities by community-based organizations in 3 cities. Public Health Rep. 2008;123 Suppl 3:101-14.
58. Operario D, Soma T, Underhill K. Sex work and HIV status among transgender women: systematic review and meta-analysis. J Acquir Immune Defic Syndr. 2008;48:97-103.

59. Des Jarlais DC, Feelemyer JP, Modi SN, Arasteh K, Hagan H. Are females who inject drugs at higher risk for HIV infection than males who inject drugs: an international systematic review of high seroprevalence areas. Drug Alcohol Depend. 2012;124:95-107.

60. Pinkham S, Stoicescu C, Myers B. Developing effective health interventions for women who inject drugs: key areas and recommendations for program development and policy. Adv Prev Med. 2012;2012:269123

61. Mathers BM, Degenhardt L, Phillips B, Wiessing L, Hickman M, Strathdee SA, et al. Global epidemiology of injecting drug use and HIV among people who inject drugs: a systematic review. Lancet. 2008;372:1733-45.

62. Beyrer C, Malinowska-Sempruch K, Kamarulzaman A, Kazatchkine M, Sidibe M, Strathdee SA. Time to act: a call for comprehensive responses to HIV in people who use drugs. Lancet. 2010;376:551-63.

63. Wood E, Werb D, Kazatchkine M, Kerr T, Hankins C, Gorna R, et al. Vienna Declaration: a call for evidence-based drug policies. Lancet. 2010;376:310-2.

64. - Strathdee SA, Hallett TB, Bobrova N, Rhodes T, Booth R, Abdool $\mathrm{R}$, et al. HIV and risk environment for injecting drug users: the past, present, and future. Lancet. 2010;376:268-84. This study examined the influence of the risk environment for people who inject drugs in reports from 2000-2009 and then modelled the potential impact of NSP, OST, and ART scale-up in 3 cities. Modelling of the impact of preventing transitions from noninjecting to injecting in Karachi and removing legal impediments to opioid substitution in Nairobi demonstrated that attention to environmental risk factors can reduce HIV risk for people who inject drugs.

65. Hawkes N. Highs and lows of drug decriminalization. BMJ. 2011;343:d6881.

66. Joint United Nations Program on HIV/AIDS. Global report: UNAIDS report on the global AIDS epidemic. Geneva: Joint United Nations Program on HIV/AIDS; 2010.

67. Stirling $\mathrm{M}$, Rees $\mathrm{H}$, Kasedde $\mathrm{S}$, Hankins $\mathrm{C}$. Introduction: addressing the vulnerability of young women and girls to stop the HIV epidemic in southern Africa. AIDS. 2008;22 Suppl 4: S1-3.

68. Castel AD, Befus M, Willis S, Griffin A, West T, Hader S, et al. Use of the community viral load as a population-based biomarker of HIV burden. AIDS. 2012;26:345-53.

69. Wood E, Kerr T, Marshall BDL, Li K, Zhang R, Hogg RS, et al. Longitudinal community plasma HIV-1 RNA concentrations and incidence of HIV-1 among injecting drug users: prospective cohort study. BMJ. 2009;338:b1649.

70. •• Das M, Chu PL, Santos G-M, Scheer S, Vittinghoff E, McFarland W, et al. Decreases in community viral load are accompanied by reductions in new HIV infections in San Francisco. PLoS One. 2010;5:e11068. This article demonstrates how community viral load data collected through a city HIV surveillance system can be used to track the epidemic and inform resource allocation. Mean and total community viral load were both significantly associated with new HIV cases from 2004 to 2008.

71. •• Tanser F, Bärnighausen T, Grapsa E, Zaidi J, Newell ML. High coverage of ART associated with decline in risk of HIV acquisition in rural KwaZulu-Natal, South Africa. Science. 2013;339(6122):96671. doi:10.1126/science.1228160. This population-based prospective cohort study followed 16,667 initially sero-negative individuals residing in the Hlabisa sub-district of KwaZulu-Natal from 2004 to 2011 of whom 1413 acquired HIV infection. The adjusted hazard of acquiring HIV declined over time as ART coverage increased through a nurse-led, public sector scale-up programme. Overall, each $1 \%$ increase in ART coverage was associated with a $1.4 \%$ decline in the risk of acquisition of new HIV infection. 
72. Henard S, Jeanmaire E, Nguyen Y, Yazdanpanah Y, Cheret A, Hoen $\mathrm{B}$, et al. Is total community viral load a robust predictive marker of the efficacy of the TasP strategy? J Acquir Immune Defic Syndr. 2012;61:400-2.

73. AVAC. Achieving the end: one year and counting [Internet]. 2012. Available at http://www.avac.org/ht/a/GetDocumentAction/i/ 47499. Accessed Jan 7, 2013.
74. Bor J, HerbstAJ, Newell ML, Bärnighausen T. Increases in adult life expectancy in rural South Africa: valuing the scale-up of HIV treatment. Science. 2013;339(6122):961-5. doi:10.1126/ science. 1230413.

75. Mills EJ, Bärnighausen T, Negin J. HIV and aging-preparing for the challenges ahead. N Engl J Med. 2012;366(14):1270-3. doi:10.1056/NEJMp1113643. 